\title{
CLINICAL USE OF LOW DOSE TADALAFIL IN COMBINATION WITH ALPHA BLOCKER IN THE MANAGEMENT OF BENIGN PROSTATIC HYPERPLASIA
}

\author{
Manish Gupta ${ }^{1}$, H. L. Guptaㄹ, Shameer Deen³, T. C. Sadasukhi4 \\ ${ }^{1}$ Assistant Professor, Department of Urology, Mahatma Gandhi Medical College and Hospital, Jaipur, Rajasthan. \\ ${ }^{2}$ Associate Professor, Department of Urology, Mahatma Gandhi Medical College and Hospital, Jaipur, Rajasthan. \\ ${ }^{3} P G$ Resident, Department of Surgery, Mahatma Gandhi Medical College and Hospital, Jaipur, Rajasthan. \\ 4 Professor \& HOD, Department of Urology, Mahatma Gandhi Medical College and Hospital, Jaipur, Rajasthan.
}

\section{ABSTRACT}

Benign Prostatic Hyperplasia associated with lower urinary tract symptoms is a common geriatric condition in males, which considerably impairs the quality of life due to the irritable and obstructive symptoms, decreased urinary flow and progression to bladder outlet obstruction. Tadalafil is a selective, reversible inhibitor of cyclic guanosine monophosphate (cGMP) - specific phosphodiesterase type 5 (PDE5). PDE5 receptor is identified in the lower urinary tract - prostate, ureter and bladder and also identified in visceral smooth muscles, skeletal muscles, platelets, kidney, lungs and cerebellum. It is well established as the first line treatment for erectile dysfunction and approved for treatment of BPH and LUTS with or without ED.

\section{OBJECTIVE}

To evaluate the efficacy of low-dose Tadalafil (5mg) along with alpha blocker in the management of Benign Prostatic Hyperplasia (BPH) and Lower Urinary Tract Symptoms (LUTS).

\section{PATIENTS AND DURATION}

The study was conducted by the Dept. of Urology, Mahatma Gandhi Medical College and Hospital, Jaipur. In this retrospective study, we reviewed the records of 60 patients in the outpatient clinic from August 2014 to August 2015 with prostatomegaly and LUTS, who were subject to a single daily dose of tamsulosin $0.4 \mathrm{mg}$ or alfuzosin $10 \mathrm{mg}$ and a daily dose of $5 \mathrm{mg}$ Tadalafil.

\section{METHOD}

Patients with LUTS and BPH who were previously managed with alpha blockers (Tamsulosin $0.4 \mathrm{mg}$ or Alfuzosin $10 \mathrm{mg}$ ) and who developed progressively bothersome symptoms with stable or increasing IPSS were included in our study by addition of $5 \mathrm{mg}$ phosphodiesterase type 5 inhibitor (Tadalafil), which has been reported by various well designed studies to be useful in the management of ED, BPH and LUTS. We analysed the International Prostate Symptom Score (IPSS), BPH Impact Index (BII) and Quality of Life (QoL). Mean age of inclusion was 45 to 80 years.

\section{RESULTS}

Before the inclusion of tadalafil in patients, patients exclusively on alpha blockers had a mean IPSS score of 23.72 (SD 1.668). IPSS improved to a mean of 11.03 (SD: 1.594, n=60, $\mathrm{p}<0.001$ ) after the addition of a single daily dose of $5 \mathrm{mg}$ tadalafil. A previous mean BPH Impact Index of 8.40 (SD: 1.167, n=60, p<0.001) improved to 4.25 (SD: 0.985, n=60, p<0.001). Quality of Life index was graded with a mean of 3.65 before addition of tadalafil and improved to a mean of 2.03 (Change: $1.62, n=60, p<0.001$ ).

\section{CONCLUSION}

Tadalafil is a newly introduced PDE5 inhibitor in the Indian scenario, present in the market for about a year. We recommend tadalafil 5mg once daily dose for BPH-LUTS patients with higher IPSS score, diabetes, smaller prostate and inoperable patients with or without Erectile Dysfunction (ED). It is safe and well tolerated and improved baseline IPSS scores and provided a positive riskbenefit profile.

\section{KEYWORDS}

Prostatic Hyperplasia, Phosphodiesterase Inhibitors, Lower Urinary Tract Symptoms, Tadalafil.

HOW TO CITE THIS ARTICLE: Gupta M, Gupta HL, Deen S, et al. Clinical use of low-dose tadalafil in combination with alpha blocker in the management of benign prostatic hyperplasia. J. Evolution Med. Dent. Sci. 2016;5(12):496-499,

Financial or Other, Competing Interest: None.

Submission 23-12-2015, Peer Review 22-01-2016,

Acceptance 28-01-2016, Published 09-02-2016.

Corresponding Author:

Dr. Manish Gupta,

Department of Urology,

Mahatma Gandhi Medical College and Hospital, RIICO,

Sitapura, Jaipur, Rajasthan.

E-mail: guptadrmanish@yahoo.com

DOI: $10.14260 /$ jemds/2016/113

\section{INTRODUCTION}

Benign prostatic hyperplasia (BPH) is a histologic diagnosis that refers to the proliferation of smooth muscle and epithelial cells within the prostatic transition zone.1,2 It is characterized by proliferation of the cellular elements of the prostate. Cellular accumulation and gland enlargement may result from epithelial and stromal proliferation, impaired preprogrammed cell death (Apoptosis), or both and is hormonally dependent upon testosterone and Dihydrotestosterone (DHT) production. 
Though considered as a part of the normal aging process in men, an estimated $50 \%$ demonstrate histopathological BPH by the age of 50 years. ${ }^{3}$ and $90 \%$ by 80 years. BPH eventually and pathologically leads to LUTS and eventually bladder outlet obstruction (BOO), LUTS clinically manifests with increased frequency of micturition, nocturia, urgency, decreased or intermittent force of stream, sensation of incomplete evacuation of bladder and less commonly retention. The condition progressively worsens due to enlargement of the gland over time and worsens peak urinary flow, voided volume and symptoms.

Besides prostatic surgery, lately treatment has been focused on the alteration of disease progression and prevention of complications that can be associated with BPH/LUTS and has been treated with various pharmacological agents as alpha-adrenergic antagonists (Alpha-blockers), 5alphareductase inhibitors (5-ARIs), cholinergics and phytotherapeutics; $5 \alpha$-reductase inhibitors block the conversion of testosterone to the more potent dihydrotestosterone and $\alpha$-blockers affect the smooth muscle tone by lowering the increased sympathetic adrenergic activity at bladder neck and prostate smooth mscles. ${ }^{4,5,6}$ Both treatment options have limited efficacy and/or unfavourable side-effects. ${ }^{7}$

Phosphodiesterase (PDE) enzymes are involved in the regulation of the nitric oxide (NO)-cyclic GMP- protein kinase pathway and are effective in reducing smooth muscle tone and are the current first-line treatment option for the majority of men with ED due to their excellent efficacy and safety profile. ${ }^{8}$ Early clinical research showed that all PDE5i are also beneficial for the treatment of LUTS. However, only tadalafil $5 \mathrm{mg}$ once daily has been approved for the treatment of BPH associated LUTS in men with or without ED. ${ }^{9}$

The American Urological Association practice guidelines on BPH from 2010 and overactive bladder from 2012 were both reaffirmed in 2014 and do not discuss PDE5I as a treatment for LUTS. 10 The European Association of Urology guidelines from 2014 on the management of non-neurogenic LUTS recommend PDE5I with or without an alpha1-blocker for moderate-to-severe (Storage and voiding) LUTS in men with or without ED (Level of evidence: 1a; Grade of recommendation: A).

Variation assessment report by Pharmacy Benefits Management Services, Medical Advisory Panel and VISN Pharmacist Executives in their "Evidence Summary and Recommendations of December 2014" consider a PDE5I in combination when symptoms are not relieved with an alpha1blocker alone. An antimuscarinic agent would not be appropriate while waiting for improvement from a 5-alphareductase inhibitor (Usually 6 to 9 months). ${ }^{11}$

\section{OBJECTIVE}

This retrospective study of 60 patients with BPH and LUTS with an IPSS score of 19-28 [Mean 23.72]; BPH impact index of 1-2 [Mean 8.40]; Quality of Life of 2-5 [Mean 3.65] who were initially managed by alpha blockers or 5-Alphareductase inhibitors and the ineffective symptomatic results and unaffected IPSS prompted the addition of PDE5 Inhibitor. We analysed the efficacy of this multimodal drug therapy.

\section{PATIENTS AND METHODS}

We studied 60 patients (Median age 58 years), reviewed as outpatients in the Department of Urology for the treatment of
BPH with LUTS from August 2014 to August 2015 in Mahatma Gandhi Medical College and Hospital, Jaipur. The study was done after clearance from the Institutional Ethics Committee.

Patients presented to the outpatient clinic with clinical features suggestive of BPH and LUTS. Patients underwent ultrasonography and uroflowmetry and their IPSS score, BPH Impact Index (BII) and Quality of Life (QoL) were assessed.

\section{Inclusion Criteria}

Were patients from the age of 45 to 80 years, who presented with clinical features of BPH, LUTS, especially with diabetes mellitus and patients impending surgical management and who were considered medically unfit were included.

\section{Exclusion Criteria}

Were patients with acute retention of urine, stricture urethra, neurogenic bladder, patients with large prostates $(>60 \mathrm{ml})$, carcinoma prostate, PSA $>10.0 \mathrm{ng} / \mathrm{mL}$ (or PSA $\geq 4.0$ to $\leq 10.0 \mathrm{ng} / \mathrm{mL}$ if malignancy had not been excluded).

The patients were subjected to a complete work up as per protocol, i.e. history taking and general physical examination to identify any anatomical disorders or congenital anomalies. Complete blood count, urine analysis, urine for culture and sensitivity, coagulation profiles, electrolyte tests, renal function tests, uroflowmetry, serum PSA were conducted along with an ultrasonography.

\section{ANALYSIS}

Efficacy was analysed by mean change in the IPSS, a scoring system to analyse the baseline characteristics in patients medically managed by alpha adrenergic blocker before inclusion of PDE5 inhibitor. Patients were also analysed by secondary measures using BPH Impact Index [BII] and IPSS Quality of Life [IPSS-QoL] adapted from American Urological Association Education and Research, Inc.[12]

\section{RESULTS}

We reviewed 60 patients with BPH and LUTS. Age of inclusion was 45 to 80 years. The mean age was 55.52. Of these, 23 (38.33\%) patients reported Erectile Dysfunction (ED), diabetes mellitus in 28 patients (46.66\%), cardiovascular disease in 30 patients (50.0\%) and hypertension in 24 patients (40.00\%) [Table 3].

Before the inclusion of tadalafil in patients, patients exclusively on alpha blockers had a mean IPSS score of 23.72 (SD 1.668). After the inclusion of tadalafil to the treatment regime, improvement of IPSS scores were noted in all patients, irrespective of ED and other co-morbid conditions. (Table 1) Incomplete emptying improved from a previous mean of 4.57 to 2.55 (Change: 2.02; SD: 0.94; $\mathrm{n}=60 ; \mathrm{p}<0.001$ ). Frequency improved from a mean of 4.02 to 1.88 (Change: 2.14; SD: 0.161; $\mathrm{n}=60 ; \mathrm{p}<0.001)$. Intermittency improved from a previous mean of 3.10 to 1.57 (Change: 1.53 ; SD: $0.073 ; n=60 ; p<0.001$ ). Urgency improved from a previous mean of 3.97 to 1.43 (Change: 2.48; SD: 0.11; $\mathrm{n}=60 ; \mathrm{p}<0.001$ ). Weak stream improved from a previous mean of 4.57 to 2.55 (Change: 2.02; SD: $0.94 ; n=60 ; p<0.001)$. Straining improved from a previous mean of 2.77 to 1.52 (Change: 1.25 ; SD: $0.029 ; n=60 ; p<0.001$ ).

Fifty six patients suffered from nocturia and after the addition of tadalafil 32 patients did not experience nocturia.

Thus, IPSS improved to a mean of 11.03 (SD: 1.594, $\mathrm{n}=60$, $\mathrm{p}<0.001$ ) after the addition of a single daily dose of $5 \mathrm{mg}$ tadalafil. 


\begin{tabular}{|c|c|c|c|c|c|c|c|c|}
\hline \multicolumn{2}{|l|}{ Group } & $\begin{array}{c}\text { Incomplete } \\
\text { Emptying }\end{array}$ & Frequency & Intermittency & Urgency & $\begin{array}{c}\text { Weak } \\
\text { Stream }\end{array}$ & Staining & $\begin{array}{l}\text { IPPS } \\
\text { Score }\end{array}$ \\
\hline \multirow{3}{*}{$\begin{array}{l}\text { Patients on Alpha } \\
\text { Blocker }\end{array}$} & $\mathrm{N}$ & 60 & 60 & 60 & 60 & 60 & 60 & 60 \\
\hline & Mean & 4.57 & 4.02 & 3.10 & 3.97 & 3.17 & 2.77 & 2.13 \\
\hline & SD & .500 & .651 & .573 & .610 & .526 & .533 & .650 \\
\hline \multirow{3}{*}{$\begin{array}{l}\text { Alpha Blocker + } \\
\text { PDE5 Inhibitor }\end{array}$} & $\mathrm{N}$ & 60 & 60 & 60 & 60 & 60 & 60 & 60 \\
\hline & Mean & 2.55 & 1.88 & 1.57 & 1.43 & 1.62 & 1.52 & .47 \\
\hline & SD & .594 & .490 & .500 & .500 & .490 & .504 & .503 \\
\hline \multirow{4}{*}{ Total } & $\mathrm{N}$ & 120 & 120 & 120 & 120 & 120 & 120 & 120 \\
\hline & Mean & 3.56 & 2.95 & 2.33 & 2.70 & 2.39 & 2.14 & 1.30 \\
\hline & SD & 1.151 & 1.215 & .938 & 1.388 & .929 & .813 & 1.017 \\
\hline & & $<0.001$ & $<0.001$ & $<0.001$ & $<0.001$ & $<0.001$ & $<0.001$ & $<0.001$ \\
\hline
\end{tabular}

BPH Impact Index (Table 2) was also analysed and revealed the following. A previous mean of 8.40 (SD: 1.167, $\mathrm{n}=60, \mathrm{p}<0.001$ ) improved to 4.25 (SD: 0.985, $\mathrm{n}=60, \mathrm{p}<0.001$ ). Physical discomfort to patients reduced from a previous mean of 2.32 to 1.20 (Change: 1.12, SD: 0.710), patients were more comfortable and less worried about their health (Mean change: 1.00, SD: $0.733, p<0.001$ ); bothersome urination reduced from a previous mean of 2.38 to 1.37 (Change: 1.0, SD: 0.705, p<0.001), patients were comfortable to do their daily work (Mean change: 0.98 , SD: 0.013 , p<0.001). Quality of Life index (Table 2) was graded with a mean of 3.65 before addition of tadalafil and improved (Mean: 2.03 , Change: 1.62 ). P value: 0.001 .

\begin{tabular}{|c|c|c|c|c|c|c|c|c|}
\hline \multicolumn{2}{|c|}{ Group } & \multirow{2}{*}{$\begin{array}{c}\text { IPPS } \\
\text { Score } \\
60\end{array}$} & \multirow{2}{*}{$\begin{array}{c}\begin{array}{c}\text { Physical } \\
\text { discomfort due } \\
\text { to urinary } \\
\text { problems }\end{array} \\
60\end{array}$} & \multirow{2}{*}{$\begin{array}{c}\begin{array}{c}\text { How } \\
\text { worried } \\
\text { about } \\
\text { health }\end{array} \\
60\end{array}$} & \multirow{2}{*}{$\begin{array}{c}\begin{array}{c}\text { How } \\
\text { bothersome } \\
\text { overall }\end{array} \\
60\end{array}$} & \multirow{2}{*}{$\begin{array}{c}\text { Have the } \\
\text { symptoms kept } \\
\text { from doing } \\
\text { work }\end{array}$} & \multirow{2}{*}{$\begin{array}{c}\text { BPH } \\
\text { impact } \\
\text { Index } \\
60\end{array}$} & \multirow{2}{*}{$\begin{array}{c}\text { QoL } \\
60\end{array}$} \\
\hline Patients on & $\mathrm{N}$ & & & & & & & \\
\hline Alpha & Mean & 23.72 & 2.32 & 1.52 & 2.38 & 2.18 & 8.40 & 3.65 \\
\hline Blocker & SD & 1.668 & .469 & .537 & .490 & .390 & 1.167 & 1.005 \\
\hline \multirow{3}{*}{$\begin{array}{c}\text { Alpha } \\
\text { Blocker + } \\
\text { PDE5 } \\
\text { Inhibitor }\end{array}$} & $\mathrm{N}$ & 60 & 60 & 60 & 60 & 60 & 60 & 60 \\
\hline & Mean & 11.03 & 1.20 & .48 & 1.37 & 1.20 & 4.25 & 2.03 \\
\hline & SD & 1.594 & .403 & .504 & .486 & .403 & .985 & .712 \\
\hline \multirow{4}{*}{ Total } & $\mathrm{N}$ & 120 & 120 & 120 & 120 & 120 & 120 & 120 \\
\hline & Mean & 17.38 & 1.76 & 1.00 & 1.88 & 1.69 & 6.33 & 2.84 \\
\hline & SD & 6.572 & .710 & .733 & .705 & .632 & 2.345 & 1.188 \\
\hline & & $<0.001$ & $<0.001$ & $<0.001$ & $<0.001$ & $<0.001$ & $<0.001$ & $<0.001$ \\
\hline \multicolumn{9}{|c|}{ Table 2: Change in BPH Impact Index and Quality of Life (QoL) } \\
\hline
\end{tabular}

On uroflowmetry analysis, patients presented with a mean Q-max of $8.96 \mathrm{~mL} / \mathrm{sec}$ and a mean post void residual volume on ultrasonography of $110 \mathrm{ml}$. Additional therapy showed positive change with good improvement in Q-max $(13.6 \mathrm{~mL} / \mathrm{sec})$ and a mean residual volume of $40 \mathrm{ml}$.

\section{Complications}

Headaches were noted in 8 patients; dyspepsia in 3 and nasopharyngitis in 5 patients. Most patients were accommodating to the additional therapy.

We summarize our findings:

1. Combination therapy resulted in significant improvement in the total IPSS. Mean change from 23.71 to 11.03 , difference $(-) 12.68$.

2. We identified good outcomes in IPSS voiding and storage scores.

3. Patients with small prostate volumes on Tamsulosin/Alfuzosin had yielded better results.

4. Significant change on uroflowmetry results were also noted along with reduced post void residual volumes on ultrasonography in the follow-up period.

The only limitation of our study is that the sample size is small and not randomized and we did not classify patients on the basis ED and DM (Diabetes mellitus) (Table 3) for the management of BPH-LUTS. We concentrated on patients with a high IPSS score. Since all the patients were already on alpha adrenergic blocker therapy, we added tadalafil to the ongoing treatment regime and did not consider a washout period of 4 weeks.

\begin{tabular}{|c|c|c|c|c|}
\hline $\begin{array}{c}\mathbf{N} \\
\mathbf{6 0}\end{array}$ & $\begin{array}{c}\text { Erectile } \\
\text { Dysfunction }\end{array}$ & Diabetes & $\begin{array}{c}\text { Hyper } \\
\text { tension }\end{array}$ & $\begin{array}{c}\text { Cardio } \\
\text { vascular } \\
\text { Disease }\end{array}$ \\
\hline Absent & 37 & 32 & 36 & 30 \\
\hline Present & 23 & 28 & 24 & 30 \\
\hline \multicolumn{4}{|c|}{ Table 3: Comorbid Conditions } \\
\hline
\end{tabular}

\section{DISCUSSION}

The results from this study demonstrate that addition of tadalafil to existing alpha blocker significantly improved LUTS and QoL in men with BPH/LUTS.

The total IPSS score and obstructive and irritative IPSS sub scores were significantly improved after tadalafil therapy in combination with alpha blocker compared with alpha blocker alone.

McVary and Colleagues [McVary et al. 2007b] reported the first double-blind, placebo-controlled trial with tadalafil in 
men with both ED and LUTS. In their randomized analysis of 281 a $1: 1$ ratio received $5 \mathrm{mg}$ of tadalafil daily (138 men, mean age: 61 years) followed by dose escalation to $20 \mathrm{mg}$ for 6 weeks or 12 weeks of placebo (143 men, mean age: 62 years). Tadalafil significantly improved the mean change from baseline IPSS at 6 weeks (5mg tadalafil-2.8 versus placebo$1.2)$ and at 12 weeks $(5 / 20 \mathrm{mg}$ tadalafil-3.8 versus placebo -1.7). Mean irritative and obstructive IPSS subscores, the IPSS QoL index, a question about urinary symptom improvement and the BPH Impact Index (BII) significantly improved.

[Broderick et al. 2010] reported on another paper again based on the same database of patients that changes in BPHLUTS after 12 weeks of treatment with placebo or various doses of once-daily tadalafil were similar in men with or without comorbid ED. After 12 weeks, changes in IPSS in men with ED (change from baseline, placebo-2.4; tadalafil 2.5, 5, $10,20 \mathrm{mg}-4.3,-4.8,-5.3,-5.6)$ and without ED $(-2.4,-3.2,-$ $5.3,-5.1,-4.5)$ were not significantly different (subgroup/interaction $p$ values: $0.352 / 0.644$ ). Similar effects were observed for IPSS QoL (With ED: $-0.6,-0.9,-0.9,-1.0$, 1.1; without ED: $-0.6,-0.7,-0.9,-0.8,-0.8 ; 0.090 / 0.773$ ) and BII (with ED: $-0.7,-0.9,-1.3,-1.3,-1.4$; without ED: $-1.0,-0.7$, $-1.3,-1.3,-1.2 ; 0.753 / 0.852)$.

Porst and Colleagues [Porst et al. 2011] reported also on the efficacy of tadalafil $5 \mathrm{mg}$ versus placebo in a randomized, double-blind, placebo controlled, 12-week study including 325 men with BPH-associated LUTS. Tadalafil $5 \mathrm{mg}$ significantly improved IPSS versus placebo $(-5.6$ versus $-3.6 ; p=0.004)$ and this improvement was apparent after 1 week and significant after 4 weeks $(-5.3$ versus $-3.5 ; p=0.003)$. The BII improvement was apparent at 4 weeks $(-1.8$ versus $-1.2 ; \mathrm{p}=$ $0.029)$ and continued at 12 weeks $(-1.8$ versus $-1.3 ; p=0.057)$. Brock and Colleagues [Brock et al. 2013] reported that tadalafil significantly reduced BPH associated LUTS compared with placebo in men without ED (IPSS -5.4 versus $-3.3, \mathrm{p}<$ 0.01 ; IPSS voiding sub score -3.5 versus $-2.0, p<0.01$; IPSS storage subscore -1.9 versus $-1.3, \mathrm{p}<0.05$ ). Tadalafil also significantly improved QoL (IPSS QoL -1.0 versus -0.7 ; BII -1.4 versus -1.0 ; both $\mathrm{p}<0.05$ )

A recent meta-analysis [Dong et al. 2013] reported that after pooling four doses $(2.5,5,10$ and $20 \mathrm{mg})$, tadalafil failed to produce a significant outcome in Qmax, although it was improved (mean difference $=+0.26 \mathrm{ml} / \mathrm{s}, \mathrm{p}=0.14$ ), but $5 \mathrm{mg}$ of tadalafil significantly improved $\mathrm{Qmax}$ (mean difference = $+0.63 \mathrm{ml} / \mathrm{s}, \mathrm{p}=0.04$ ). McVary commented that it might be a potential new basic pathophysiology paradigm in which the impact of PDE5 activity on LUTS symptoms may reveal an alternate explanation for the aetiology of LUTS not involving relaxation of prostatic smooth muscle, but bladder compliance changes, improvement in bladder wall perfusion or central nervous system impact [McVary, 2006]. Donatucci and Colleagues [Donatucci et al. 2011] reported on the long-term efficacy of tadalafil.

A total of 427 men who completed the 12-week, placebocontrolled, dose-finding study assessing once-daily tadalafil $(2.5,5,10$ or $20 \mathrm{mg})$ or placebo elected to continue into the open-label extension period using tadalafil $5 \mathrm{mg}$. Changes in the total IPSS, IPSS irritative and obstructive subscores, IPSS health-related QoL and BII were maintained after 1 year and were similar despite the tadalafil dose administered during the double-blind study. During the open-label extension period, mean PSA increased from $1.6 \pm 1.3$ to $1.8 \pm 1.4 \mathrm{ng} / \mathrm{ml}$ Mean PVR was $61.1 \pm 60.4 \mathrm{ml}$ at study entry and $42.2 \pm 64.1 \mathrm{ml}$ after the open-label extension period. Therefore, it can be concluded that the efficacy of tadalafil is maintained for at least 1 year.

\section{CONCLUSION}

Tadalafil is a newly introduced PDE5 inhibitor in the Indian scenario, present in the market for about a year. We recommend tadalafil $5 \mathrm{mg}$ once daily dose for patients with BPH-LUTS with or without ED, higher IPSS score, diabetics and inoperable patients. It is safe and well tolerated and improved baseline IPSS scores and provided a positive risk-benefit profile.

\section{REFERENCES}

1. Hansen BJ, Flyger H, Brasso K, et al. Validation of the selfadministered Danish Prostatic Symptom Score (DAN-PSS1) system for use in benign prostatic hyperplasia. BIJU 1995;76:451-458.

2. Barry M; Fowler F, Jr; O'Leary M, et al. Measurement Committee of the American Urological Association. Med Care 1995;22:AS145.

3. Norman RW, Nickel JC, Fish D, et al. Prostate-related symptoms in Canadian men 50 years of age and older: prevalence and relationships among symptoms. Br J Urol 1994;74:542-550.

4. McVary KT. Medical therapy for benign prostatic hyperplasia progression. Curr Urol Rep 2002;3:269-275.

5. Schulman CC. Lower urinary tract symptoms/benign prostatic hyperplasia: minimizing morbidity caused by treatment. Urology 2003;62 (Suppl 3):24-33.

6. Madersbacher S, Marszalek M, Lackner J, et al. The longterm outcome of medical therapy for BPH. Eur Urol 2007;51:1522-33.

7. Carbone DJ, Jr; Hodges S. Medical therapy for benign prostatic hyperplasia: sexual dysfunction and impact on quality of life. Int J Impot Res 2003;15:299-306.

8. Hatzimouratidis K, Amar E, Eardley I, et al. (2010). Guidelines on male sexual dysfunction: erectile dysfunction and premature ejaculation. Eur Urol 57:804814.

9. McVary K, Roehrborn C, Kaminetsky J, et al. (2007b). Tadalafil relieves lower urinary tract symptoms secondary to benign prostatic hyperplasia. J Urol 177:1401-1407.

10. McVary KT, Roehrborn CG, Avins AL, et al. Update on AUA guideline on the management of benign prostatic hyperplasia. J Urol 2011;185:1793-1803.

11. https://vaww.cmopnational.va.gov/cmop/PBM/default.a spx - Accessed September 20th 2015.

12. American Urological Association Education and Research, Inc. McVary K, Roehrborn C, Avins A, et al. American Urological Association Guideline: Management of Benign Prostatic Hyperplasia (BPH), Revised 2010. Linthicum, MD; 2010. 